\title{
UN COLECCIONISTA CRIOLLO EN LA LIMA DEL SIGLO XVIII: PEDRO JOSÉ BRAVO DE LAGUNAS (1703-1765)
}

\section{A CREOLE COLLECTOR AT LIMA IN THE $18^{\text {th }}$ CENTURY: PEDRO JOSÉ BRAVO DE LAGUNAS (1703-1765)}

\author{
Antonio Holguera CABrera \\ holguera1991@hotmail.com
}

\begin{abstract}
El análisis de los testamentos e inventarios de bienes ofrece una detallada información sobre las obras de arte existentes en un centro artístico, aportando mayor conocimiento del gusto de una época y el desarrollo del coleccionismo. Un ejemplo es Pedro José Bravo de Lagunas (1703-1765), un interesante coleccionista que adquirió más de 100 pinturas en la Lima del siglo XVIII.

Palabras clave: inventarios de bienes; coleccionismo; pintura; Lima; siglo XVIII.
\end{abstract}

The analysis of wills and goods inventories offers a detailed information about works of art existing in an artistic center, contributing to a greater knowledge of the taste of an era and the development of collecting. An example is Pedro José Bravo de Lagunas (1703-1765), an interesting collector who acquired more than 100 paintings at Lima in $18^{\text {th }}$ century.

Keywords: goods inventories; collecting; painting; Lima; $18^{\text {th }}$ century.

\section{INTRODUCCIÓN}

El interés sobre el coleccionismo pictórico ha sido demostrado en Europa por la publicación de varios estudios en el último tercio del siglo XX. Schlosser ya afirmó que el acto de coleccionar puede rastrearse desde la Antigüedad, y que debía considerarse un fenómeno en constante evolución, con unas fórmulas y criterios específicos para atesorar según la época histórica en la que nos 
situemos ${ }^{1}$. Siguiendo la evolución del gusto en grupos y particulares se dio forma a una historia del coleccionismo en ensayos donde imperaba el sentido cronológico, e incluso el análisis de las motivaciones psicológicas ${ }^{2}$. Concretamente, el coleccionismo artístico interesó -e interesa- a la Historia del Arte porque ofrece la posibilidad de aportar mayor luz sobre el gusto artístico en un espacio y tiempo determinado.

En el ámbito hispanoamericano el tema del coleccionismo ha sido tratado desde los años ochenta y noventa de la pasada centuria, en relación a la élite cuzqueña y limeña, formada por individuos que adquirieron una buena posición en la administración virreinal, es decir, catedráticos de Universidad, funcionarios y

1 VON SCHLOSSER, Julius: Las cámaras artísticas y maravillosas del renacimiento tardío: una contribución a la historia del coleccionismo. Torrejón de Ardoz, 1988, pp. 13ss. Hemos de remontarnos al siglo XVII para atestiguar una evolución en los criterios de acumulación, pasándose progresivamente del eclecticismo presente en las cámaras de maravillas a la especialización de las galerías pictóricas, conservadas en palacios y viviendas particulares en la que los dueños valoraban las cualidades estéticas de sus adquisiciones. Finalmente, a mediados del siglo XVIII aparecen los primeros intentos de dar un orden más riguroso a lo atesorado y se produce la separación entre la obra de arte y el objeto científico. Cfr. CABELLO CARRO, Paz: "La formación de las colecciones americanas en España: evolución de los criterios", Anales del Museo de América, 9, 2001, pp. 303-318; y CABELLO CARRO, Paz: Coleccionismo americano indígena en la España del siglo XVIII. Madrid, 1989.

${ }^{2}$ Consultar las visiones globales ofrecidas en MORÁN TURINA, José Miguel y CHECA CREMADES, Fernando: El coleccionismo en España: de la cámara de las maravillas a la galería de pinturas. Madrid, 1985; CANO DE GARDOQUI GARCÍA, José Luis: Tesoros y colecciones: orígenes y evolución del coleccionismo artístico. Valladolid, 2001; y JIMÉNEZ-BLANCO, María Dolores: El coleccionismo de arte en España. Una aproximación desde su historia y su contexto. Barcelona, 2013. Otros investigadores han centrado sus esfuerzos en coleccionistas particulares, como SAGASTE ABADÍA, Delia: "Naturam et artem sub uno tecto. Las colecciones pictóricas del ilustrado Pedro Franco Dávila (1711-1786)", Artigrama, 24, 2009, pp. 391-411; DOMÍNGUEZ ARRANZ, María Almudena: "Nada es más hermoso que conocer: Lastanosa, entre el anticuarismo y la erudición", Saguntum: Papeles del Laboratorio de Arqueología de Valencia, 40, 2008, pp. 205-218; ILLÁN MARTÍN, Magdalena: "Un desconocido coleccionista en la Sevilla del siglo XVIII: Tomás Mácores", Laboratorio de Arte, 18, 2005, pp. 417-424; y MARTÍNEZ CUESTA, Juan: "El Infante Don Gabriel de Borbón y su actividad como mecenas de pintura", Boletín del Museo del Prado, 30, 1991, pp. 39-61. La psicología del coleccionismo se aborda tanto en estudios clásicos como recientes, demostrando que no ha perdido vigencia. MARÍN BOZA, Pedro: "Colecciones y pasiones. Sobre el psicoanálisis, el género y los principios motivadores del coleccionismo", Goya, 351, 2015, pp. 116-127; BLOM, Philipp: El coleccionista apasionado: una historia íntima. Barcelona, 2013; SÁNCHEZ, Ivette: Coleccionismo y literatura. Madrid, 1999; y CODET, Henri: Ensayo sobre el coleccionismo. París, 1921. 
comerciantes $^{3}$. En varias ocasiones el asunto ha sido abordado de manera secundaria, relacionándose con la pintura, escultura e intercambios comerciales. No obstante, la cuestión fue ganando especificidad en la Nueva España, a través del análisis de testamentos e inventarios de bienes, tendencia que se ha mantenido hasta la actualidad ${ }^{4}$. En el contexto peruano, los acercamientos a la cultura material de los sectores poderosos son más frecuentes desde el cambio de siglo, siguiendo una línea de continuidad que invita a elaborar ensayos ilustradores de un fenómeno necesitado de una visión de conjunto ${ }^{5}$. Este artículo pretende se-

${ }^{3}$ Cfr. RIZO-PATRÓN BOYLAN, Paul: "El coleccionismo privado durante la colonia. Signo de expansión cultural", en Actas del Coloquio Internacional Sociedad y Expansión. Vol. I. Lima, 1994, pp. 345-353; y WUFFARDEN, Luis Eduardo: "La catedral de Lima y el triunfo de la pintura", en La Basílica Catedral de Lima. Lima, 2004, pp. 241-317. Para Cuzco, GUIVOBICH PÉREZ, Pedro: "El testamento e inventario de bienes de Espinosa Medrano", Revista Histórica, 1, 1992, pp. 1-31; VILLANUEVA URTEAGA, Horacio: "Los Mollinedo y el arte del Cuzco colonial", Boletín del Instituto Riva-Agüero, 16, 1989, pp. 209-219; DE MESA, José y GISBERT, Teresa: Historia de la pintura cuzqueña. Vol. I. Lima, 1982, pp. 118-123; y WUFFARDEN, Luis Eduardo: "Las visitas del obispo Mollinedo y sus políticas visuales: una fuente para la historia del arte colonial andino", en Sociedad y gobierno episcopal. Las visitas del obispo Manuel de Mollinedo y Angulo (Cuzco, 1674-1694). Lima, 2008, pp. 41-67.

${ }^{4}$ Véase la tesis inédita GONZÁLEZ GARCÍA, Pedro José: El coleccionismo pictórico de las élites de poder en Nueva España a principios del siglo XVII. Vols. I, II y III. Dirigida por Emilio Gómez Piñol y defendida en la Universidad de Sevilla, 1991. El coleccionismo mexicano no está exento de aproximaciones, como demuestran algunos artículos y monografías que tratan este asunto. GARDUÑO, Ana: El poder del coleccionismo de arte: Alvar Carrillo Gil. México, 2009; y GARDUÑO, Ana: "El coleccionismo decimonónico y el Museo Nacional de San Carlos”, Anales del Instituto de Investigaciones Estéticas, 93, 2008, pp. 199-212.

${ }^{5}$ En este sentido, a los títulos recogidos en la nota 4 pueden sumarse DUNBAR TEMPLE, Ella: "El inventario de la Quinta de Presa", Documenta, Revista de la Sociedad Peruana de Historia, 1, 1948, pp. 317-374; RAMOS SOSA, Rafael: "El cabildo catedral de Lima: los gustos artísticos de una élite intelectual (1600-1630)", en Élites urbanas en Hispanoamérica: de la conquista a la independencia. Sevilla, 2005, pp. 397-400; STANFIELDMAZZI, Maya: "The Possessor's Agency: Private Art Collecting in the Colonial Andes", Colonial Latin American Review, 18, 3, 2009, pp. 339-364; MONTES GONZÁLEZ, Francisco: "Nobleza y mecenazgo artístico: virreyes andaluces en Indias", en La nobleza andaluza y su proyección en Indias. Sevilla, 2013, pp. 117-156; JIMÉNEZ JIMÉNEZ, Ismael: "La colección pictórica americana del duque de la Palata, virrey del Perú", Cuadernos de Arte, 45, 2014, pp. 113-128; BARRIGA CALLE, Irma: "Modernos e ilustrados: sensibilidad y buen gusto en el Perú del siglo XVIII", en El Perú en el siglo XVIII. La Era Borbónica. Lima, 2015, pp. 423-447; y WUFFARDEN, Luis Eduardo: "El Palacio de Torre Tagle y sus colecciones artísticas", en El Arte de Torre Tagle. La colección del Ministerio de Relaciones Exteriores del Perú. Lima, 2016, pp. 19-40. Ver concretamente pp. 27-31 y los trabajos de Emilio Gutiérrez de Quintanilla expuestos en su bibliografía. 
guir el camino que ha comenzado a trazarse en los últimos veinte años en relación al coleccionismo americano. El objetivo es dar a conocer la serie de pinturas que refiere en su testamento Pedro José Bravo de Lagunas (1703-1765), un personaje perteneciente a la élite. Gracias a ello se espera establecer una valoración de su papel como coleccionista, hipotetizar sobre el gusto artístico en la Lima del siglo XVIII y ofrecer una nueva línea de trabajo para estudiar con precisión y rigor la poco conocida pintura limeña, apoyando otros trabajos que tienen como objetivo construir una visión sistemática de la misma, como desde hace algunos años ya se ha conseguido en otros centros artísticos de Hispanoamérica ${ }^{6}$.

\section{EL COLECCIONISTA Y SU ÉPOCA}

El doctor don Pedro José Bravo de Lagunas (1703-1765) nació en Lima y fue bautizado el 1 de octubre de 1703 en la parroquia del Sagrario de esta misma ciu$\mathrm{dad}^{7}$. Sus padres fueron el maestre de campo don Pedro Bravo de Lagunas y Bedoya, corregidor de Piura, y doña Mariana de Castilla y Loaisa, ambos limeños ${ }^{8}$. Tuvo por abuelos a don Fernando Bravo de Lagunas, caballero de la orden de Calatrava y contador mayor del Real Tribunal de Cuentas, y a Antonia Vergara. Por la genealogía sabemos que procedía de conquistadores de Lima, perteneciendo a una familia acomodada de la ciudad de Los Reyes que le facilitó acceder a altos cargos de la administración virreinal. Como hermano legítimo tuvo a don José Toribio Bravo de Lagunas y Castilla, con el que trató todos los asuntos de su testamento, incluyendo el destino de la colección pictórica.

Realizó los estudios en los colegios de San Martín y Real de San Felipe, en el que fue nombrado rector en 1728. Además, ejerció como catedrático de prima de leyes y de cánones de la Universidad de San Marcos, y fue asesor de los virreyes José de Almendáriz, I marqués de Castelfuerte (1724-1736), y de José Antonio de Mendoza Caamaño y Sotomayor, marqués de Villagarcía (1736-1745). Entre los

${ }^{6}$ Como en el caso de la escuela cuzqueña en DE MESA, J. y GISBERT, T.: Historia de..., op. cit. Recientemente ha habido un renovado interés por reunir en importantes volúmenes todo lo conocido sobre la pintura limeña. ALCALÁ, Luisa Elena y BROWN, Jonathan: Pintura en Hispanoamérica: 1550-1820. Madrid, 2014; y STASTNY, Francisco: Estudios de arte colonial. Vol. I. Lima, 2013.

7 LOHMANN VILLENA, Guillermo: Los ministros de la Real Audiencia de Lima en el reinado de Los Borbones (1700-1821). Sevilla, 1974, p. 16.

${ }^{8}$ DE MENDIBURU, Manuel: Diccionario histórico- biográfico del Perú. T. II. Lima, 1876, p. 76. Para más información sobre su biografía, DE LAVALLE, José Antonio: "Pedro José Bravo de Lagunas y Castilla (apuntes sobre su vida y sus obras)", en Estudios Históricos. Lima, 1935, pp. 147-194; y SÁNCHEZ-CONCHA BARRIOS, Rafael: "Ascendencia y colateralidad del virtuoso limeño Alonso Messía Bedoya de la Compañía de Jesús (1655-1732)”, Hidalguía: la revista de genealogía, nobleza y armas, 321, 2007, pp. 243 270. 
cargos más importantes de su dilatada trayectoria destacan el de oidor de la Real Audiencia de Lima (1746) y consejero honorario del Consejo de Indias (1763)9. Debió de ser un hombre erudito porque escribió sobre materias históricas y de jurisprudencia, imprimiéndose en Lima varios de esos textos en la Colección Real (1761). Dedicó a la Audiencia el Voto consultivo sobre los trigos de Lima (1755) junto a varios dictámenes ${ }^{10}$. Confirió poder para testar el 27 de agosto de 1751, en cuya conformidad se extendió su testamento el 29 de diciembre de 1765 ante Orencio de Azcarrunz y los testigos don Domingo de Toledo y don Carlos de Angulo Varorra ${ }^{11}$.

El testamento de Bravo de Lagunas se articula, como es frecuente en este tipo de documentos, con sus datos, estado de salud y deseos sobre las misas a celebrar una vez fallecido, uniéndose una serie de cláusulas que se centran en la afirmación de la fe y la aceptación del misterio de la Santísima Trinidad: "En el nombre de Dios todopoderoso en cuya gracia todas las cosas tienen buen principio loable y dichoso fin. Creyendo como firme fiel y verdaderamente creo y confieso el Misterio de la Santísima Trinidad, Padre, Hijo y Espíritu Santo"12. En relación al entierro dispone que la misa se haga de cuerpo presente en el colegio de la Compañía de Jesús o en la iglesia de Nuestro Señor de la Buena Muerte, "con la mayor humildad con solo quatro velas y un paño en el suelo sin pompa"13. Por lo comentado parece ser que su selectivo gusto artístico convivía con una fe profunda y viva.

Su período de madurez y éxito profesional coincidió con el segundo tercio del siglo XVIII, época que vaticinaba el crepúsculo del virreinato peruano ${ }^{14}$. Tras el cambio de dinastía que se había dado en España se produjo en Lima una modernización de la economía siguiendo los postulados ilustrados. Una vez firmado el Tratado de Utrecht (1713-1715), se aceptó la legalidad del contrabando a través de los navíos de servicio, según real cédula de 11 de enero de 1701, y se generaron cambios en la corriente comercial. Buenos Aires consiguió en 1720 recibir el comercio de Europa, ocasionando que Lima dejara de ser el centro distribuidor y que perdiese el mercado de la Plata. El fin último fue disminuir los trámites y lograr una mayor flexibilización en cuestiones comerciales, pero a costa de que Lima quedase sin abastecimiento de productos de primera necesidad, ocasionando un aumento de precios. Con el paso de los años la situación empeoró

${ }^{9}$ LOHMANN VILLENA, G.: Los ministros..., op. cit., pp. 17-18.

${ }^{10}$ DE MENDIBURU, M.: Diccionario..., op. cit., p. 76.

11 Archivo General de la Nación (A.G.N.), sección Protocolos Notariales de Lima, protocolos de Orencio de Azcarrunz, no 83, 29-12-1765, f. 480r.

${ }^{12}$ Ibidem, f. $477 \mathrm{r}$.

13 Ibid., f. 478r.

${ }^{14}$ NAVARRO GARCÍA, Luis: "Crepúsculo del Virreinato Peruano", en Hispanoamérica en el siglo XVIII. Sevilla, 1991, pp. 101-115. 
debido a las disposiciones liberalizadoras promulgadas en los años sesenta cuya misión fue fomentar el comercio transatlántico ${ }^{15}$.

A esto se unió la inseguridad provocada por los ataques piráticos como el ocurrido en 1739 cuando la expedición de Anson acabó por arruinar un país que ya estaba dinamitado por la presencia de británicos desde comienzos de siglo, como William Dampier en 1704 o Woodes Rogers en 1710. Además el terremoto de 1746, bajo el gobierno del virrey José Antonio Manso de Velasco, conde de Superunda (1745-1761), aunque generó un impulso de renovación urbanística y la fundación de centros de actividad científica y cultural, supuso también una catástrofe económica. El descontento "provocó una fuerte actitud crítica y una acción de protesta contra el gobierno primero y contra el régimen monárquico finalmente. Se siguió combatiendo el despotismo para tratar de romper el centralismo borbónico, el militarismo y el mercantilismo hasta la última década del siglo en que se advierte una mayor influencia de la ideología liberal y enciclopedista" ${ }^{16}$. En este sentido, "son notables los frecuentes amotinamientos de indios y la muerte de sus corregidores, cuyo gobierno y cuyos ilegales y abusivos repartimientos daban lugar a protestas radicales"17: rebelión de Cochabamba (1730), Oruro (1739), Tarma (1742), entre otras. En este contexto ilustrado y de inestabilidad hay que situar a Pedro José Bravo de Lagunas y su colección.

\section{EL COLECCIONISMO LIMEÑO: APROXIMACIÓN A UNA COLECCIÓN PICTÓRICA DE LA SEGUNDA MITAD DEL SIGLO XVIII}

El coleccionismo limeño del siglo XVIII podría situarse, por ahora, dentro del espíritu del coleccionista de la Edad Moderna. Más concretamente parece relacionarse, como veremos en los datos referidos posteriormente, con el tipo de coleccionismo desarrollado en la metrópoli durante los siglos del Barroco. Por supuesto esta afirmación espera ser respaldada o desmentida en un futuro con el examen de otras fuentes documentales de idéntica naturaleza para aceptar una tendencia general. Durante los siglos XVII y XVIII, las colecciones europeas se ligaban a las clases sociales del Antiguo Régimen y a la burguesía enriquecida que, primero en el opulento escenario de los Países Bajos y después en otras ciudades abiertas al comercio como Sevilla, comenzaron a decorar sus casas con

${ }^{15}$ Para el estudio de los condicionantes de las reformas borbónicas, sus causas y consecuencias conviene señalar ACEVEDO, Edberto Óscar: Ilustración y liberalismo en Hispanoamérica. Buenos Aires, 2010; MUÑOZ PÉREZ, Juan: "La Ilustración americana", en Carlos III y la Ilustración. Vol. I. Madrid, 1988, pp. 401-414; y VARGAS UGARTE, Rubén: Historia del Perú. TT. III y IV. Buenos Aires, 1956-1957.

${ }^{16}$ EUGENIO MARTÍNEZ, María de los Ángeles: La ilustración en América (siglo XVIII): pelucas y casacas en los trópicos. Madrid, 1988, p. 36.

17 NAVARRO GARCÍA, L.: "Crepúsculo...”, op. cit., p. 110. 
pinturas como símbolo de su nuevo estatus social, otorgando al espacio doméstico un mayor refinamiento ${ }^{18}$. Esta práctica nace de la formación de los gabinetes de pintura del archiduque Leopoldo Guillermo y del papel que iba adquiriendo el artista como profesional libera $1^{19}$. Estas dos realidades deben tenerse en cuenta al analizar la colección de Pedro José Bravo de Lagunas, formada completamente de pinturas y situada en su domicilio. No obstante, como hemos comentado, los datos del testamento hay que tratarlos cautelosamente, a la espera de que nuevas fuentes arrojen más claridad a este hipotético panorama.

Como punto de referencia general podemos ver la importante actividad comercial desarrollada en Sevilla en gran parte del siglo XVII ${ }^{20}$. A través de ella podría afirmarse que la adquisición de pinturas en el mercado no era exclusiva de la nobleza y del alto clero sino que en la misma participaron comerciantes y funcionarios, existiendo una importante diversificación, potencialidad y coherencia del mercado artístico. Cada individuo, atendiendo a sus inquietudes, y en relación con el grupo social del que formaba parte, tenía más predilección por una temática u otra: los comerciantes, por ejemplo, obtenían normalmente obras de carácter devocional, mientras que el grupo de los funcionarios demostraba, en general, un gusto polifacético obteniendo tanto cuadros de tema religioso como profano, tendencia que sigue Pedro José Bravo de Lagunas.

Sevilla fue una ciudad que demandó temas sagrados y al mismo tiempo, por su condición de ciudad mercantil, se fue abriendo a nuevos géneros a través de una doble vía de penetración: los Países Bajos y el coleccionismo emprendido desde la corte madrileña por Felipe IV $^{21}$. Durante los siglos XVII y XVIII el mercado

${ }^{18}$ En el caso español se conservan descripciones de los interiores domésticos, como recoge Cassiano dal Pozzo, copero y secretario real del cardenal Francesco Barberini, con motivo de su estancia en Madrid (1626). Ilustrativa es la casa de los marqueses de Esquilache, que despertó auténtica admiración por tener en propiedad, entre otras piezas, una tabla de Guido Reni y un San Jerónimo de Correggio. Cfr. SIMÓN DÍAZ, José: "El arte en las mansiones nobiliarias madrileñas en 1626", Goya, 154, 1980, pp. 200-205. Consúltese para la casa limeña y distribución del ajuar doméstico CRESPO RODRÍGUEZ, María Dolores: Arquitectura doméstica de la ciudad de Los Reyes: (1525-1750). Sevilla, 2006, pp. 297-340.

${ }^{19}$ Para el tema de los gabinetes de pinturas, DÍAZ PADRÓN, Matías: David Teniers, Jan Brueghel y los gabinetes de pinturas. Madrid, 1992. Véase sobre la liberalidad de la pintura GÁLLEGO, Julián: El pintor, de artesano a artista. Granada, 1995; y MARTÍN GONZÁLEZ, Juan José: El artista en la sociedad española del siglo XVII. Madrid, 1984.

${ }^{20}$ Véase MÉNDEZ RODRÍGUEZ, Luis: Velázquez y la cultura sevillana. Sevilla, 2005, pp. 125-140.

${ }^{21}$ El coleccionismo emprendido en la corte madrileña fue un punto de referencia para la formación de otras colecciones europeas y debió de serlo para las cortes virreinales de México y Lima. También contribuyó a la consolidación de los modos del comercio internacional durante el Barroco. En este sentido Felipe IV asumió el papel de gran 
pictórico peninsular confirma una situación de evidente contraste entre la tratadística y los hábitos adquisitivos porque aunque existió una rigurosa clasificación de los géneros, considerándose en segundo orden de importancia el paisaje y el bodegón, las referencias documentales parecen demostrar que las representaciones laicas fueron de interés para los sectores urbanos ${ }^{22}$. Aunque suele prevalecer el espíritu devocional propio del catolicismo -recordemos que el término "países" puede hacer referencia a paisajes con figuras religiosas-, es perceptible un giro hacia lo profano que eclosionó en el siglo XVIII, sin ser exclusivo de dicha centuria y confirmando una tendencia constatable durante el Seiscientos.

No hay que olvidar además el activo intercambio entre la metrópoli y las posesiones ultramarinas, tanto de obras de arte como de artistas, que demuestra una eficaz cohesión entre los territorios ${ }^{23}$. Lo comercial tuvo su influencia en lo artístico, como se aprecia especialmente en la aceptación que tuvo la corriente estética del naturalismo sevillano que influyó decisivamente en los temas pintados en la ciudad de Los Reyes, concretamente en los claustros conventuales y en los interiores de los templos ${ }^{24}$. Muchas piezas estaban a la vista y pudieron influir en el

protector de las artes convirtiéndose en el más destacado coleccionista de pinturas de la época. BROWN, Jonathan: El triunfo de la pintura: sobre el coleccionismo cortesano en el siglo XVII. Madrid, 1996.

${ }^{22}$ Un género era mejor considerado si en él tenía cabida la figura humana. El dominio de su representación distinguía la valía de los pintores. Por eso, la pintura de historia -normalmente religiosa - tuvo una gran aceptación. Francisco Pacheco llegó a considerar el bodegón un género menor y poco desafiante. Véase PACHECO, Francisco: Arte de la Pintura. Madrid, 2001, p. 125. Debido a la evolución de la pintura como actividad liberal, se aceptaba al pintor como un intelectual que debía saber dibujar. Para ciertos tratadistas, como Vicente Carducho, algunos géneros abusaban de la masa de color y eran menos estimados: "pinturas por faltarle el dibujo no son de estimación ni precio. Del que se sigue que el dibujo hace buena pintura". Ver CARDUCHO, Vicente: Diálogos de la Pintura. Madrid, 1979, p. 249.

${ }^{23}$ A finales del siglo XVI destaca en Perú la figura de Mateo Pérez de Alesio (15471628), que tras pasar algún tiempo en Sevilla se traslada a Lima. A principios del XVII encontramos a Miguel Güelles (act. 1607-1637) y Domingo Carro trabajando en una serie de cuarenta y un lienzos dedicados a la vida de Santo Domingo de Guzmán para el convento de Santo Domingo de Lima. Finalmente, en el tránsito del siglo XVIII al XIX, está la figura de José Joaquín del Pozo, colaborador de Matías Maestro (1776-1865), entre cuyas obras destaca Los desposorios místicos de Santa Rosa en el transepto de la iglesia de Santo Domingo.

${ }^{24}$ Por ejemplo las pinturas conservadas en el claustro del convento de San Francisco de Lima, con escenas de la vida de San Francisco, fue pintada por Francisco de Escobar, Diego de Aguilera, Andrés de Liébana y Pedro Fernández de Noriega con un total de 39 lienzos, contratados en 1670. WUFFARDEN, Luis Eduardo: "Surgimiento y auge de las escuelas regionales, 1670-1750", en Pintura en Hispanoamérica: 1550-1820. Madrid, 2014, pp. 311-314. También de enorme trascendencia en el cambio de rumbo que tomaría la 
gusto de los nacidos en el Nuevo Mundo. Por todo lo que venimos diciendo pudo ser posible, y la elección de asuntos en la colección de Pedro José Bravo de Lagunas es prueba de ello, que en la cuestión temática España y Lima siguieran patrones parecidos, aunque será necesario buscar más ejemplos para aceptar una tendencia general ${ }^{25}$.

A esto hay que añadir que Bravo de Lagunas fue una personalidad sumamente culta, un hombre de letras, catedrático de Universidad y dueño de una importante biblioteca ${ }^{26}$. Participó activamente en la difusión de los ideales ilustrados y por su testamento se muestra como un individuo sensible y conocedor del arte de la pintura, seleccionando una serie de ejemplos de calidad para ser vinculados en el momento de su muerte. Existió en él la actitud propia del coleccionista moderno, basada, no en la mera acumulación de objetos de diferente naturaleza, sino en una selección coherente, resultado de una conciencia estética plenamente desarrollada. Además, estuvo en contacto con Cristóbal Lozano (1705-1776), pintor limeño de los más estudiados e influyentes en el siglo XVIII, de cuya actividad artística surgió una amplia nómina de seguidores que copiaron sus modelos como José Joaquín Bermejo (act. 1760-1792) y Cristóbal de Aguilar.

pintura limeña durante el siglo XVII fue la serie de cuarenta y un lienzos pintada por Miguel Güelles (act. 1607-1637) y Domingo Carro, conservada en el convento de Santo Domingo de Lima (1608). Cfr. HALCÓN, Fátima: "El pintor Juan de Uceda: sus relaciones artísticas con Sevilla y Lima”, Laboratorio de Arte, 15, 2002, pp. 373-381; y STASTNY, Francisco: Conjunto Monumental de Santo Domingo. Lima, 1998.

${ }^{25}$ El afán coleccionista en Lima es comparable al de otros centros culturales del, por entonces, extenso virreinato peruano como Cuzco o Quito. Así, por ejemplo, tenemos noticias de una notable colección de 97 ejemplares, fechada hacia 1760 y perteneciente a Juana de Osquendo, viuda de Gaspar de Zedillo, corregidor de Cuzco. En su vivienda particular conservó un apostolado completo, una serie de la vida de la Virgen y países alusivos a la Creación junto a imágenes de Cristo, San Antonio de Padua y advocaciones marianas. Véase GUTIÉRREZ, Ramón et al.: La casa cusqueña. Argentina, 1981, p. 52. En Quito podría comentarse el trabajo de JUSTO ESTEBARANZ, Ángel: Pintura y sociedad en Quito en el siglo XVII. Quito, 2011. A partir de documentación inédita el autor demuestra la existencia de un variado "corpus" temático e informa sobre el bajo costo de la producción quiteña en la segunda mitad del siglo XVII. En este sentido el valor monetario dependía de las dimensiones, calidades de la marquetería, género y autoría, siendo Miguel de Santiago, un desconocido autor llamado Chiriboga y Juan Espinosa Esteban de los Monteros aquellos que gozaron de mejor consideración. Véase concretamente las pp. 96-114 de esta investigación, citadas en la nota 4 de un trabajo reciente sobre este mismo particular: WEBSTER, Susan V.: "Materiales, modelos y mercado de la pintura en Quito, 15501650", Procesos: revista ecuatoriana de historia, 43, 2016, pp. 37-64.

${ }^{26}$ Hace constar en su testamento que sus libros fuesen legados a los padres de la congregación o sacerdotes pobres: "Todos los libros de moral, canónicos, de historia, o curiosos de erudición, se separasen a la librería de la congregación”. A.G.N., Protocolos de..., op. cit., f. 485 r. 
Por esta razón ha querido tomarse como un punto de referencia para artistas de su generación. Lozano hizo escuela en la pintura religiosa, con composiciones dinámicas y plenas de color, y también en el retrato, de gran calidad, recogiendo las influencias emanadas de la corte absolutista francesa desde mediados del siglo XVII como se aprecia en el retrato ecuestre del virrey conde de Superunda conservado en el Museo de América de Madrid ${ }^{27}$.

En la colección de la Casa Aliaga se conserva el retrato de mayor calidad de Pedro José Bravo de Lagunas, pintado en 1752 por Lozano, pocos años antes de la redacción del testamento (Figura 1$)^{28}$. Por otra parte, en la memoria de las pinturas se hace referencia a la posesión de retratos de la primera época de Lozano, como los de José Antonio de Mendoza, marqués de Villagarcía, los de sus hijos don Álvaro de Mendoza y el marqués de Monroy y el del sobrino de Bravo de Lagunas, el conde de Villa Señor ${ }^{29}$.

Pedro José Bravo de Lagunas es presentado de cuerpo entero, en el interior quizás de un despacho que queda enmarcado por un ampuloso cortinaje recogido en un lado. Ocupa el primer plano de la composición, adelantándose con respecto al resto de objetos que componen la escena con un movimiento artificial de los pies que es típico en este tipo de retratos de aparato, al igual que la teatralidad en el movimiento de las manos, tensas y de dedos largos. El ilustre catedrático parece haber sido sorprendido en un momento de esparcimiento que dota a la pieza del valor de una instantánea. El tratamiento del rostro refleja el avance del naturalismo ya conseguido en algunos retratos del siglo XVII, captándose la individualidad física y psicológica de Bravo de Lagunas, habilidad en la que destacó Lozano. La expresión es obtenida a través de un dibujo seguro que resalta los perfiles y es empleado para darle presencia y corporeidad al efigiado.

Los labios finos y relajados, esbozando una media sonrisa invita a un diálogo con el espectador al transmitir un carácter afable que contrasta con la severidad

${ }^{27}$ Para conocer más sobre Cristóbal Lozano, ESTABRIDIS CÁRDENAS, Ricardo: "Obras firmadas de Cristóbal Lozano para los jesuitas", Mana Tukukuq ILLAPA, 10, 2013, pp. 36-47; "Academia y academicismos en Lima decimonónica", Tiempos de América, 11, 2004, pp. 77-90; "El retrato del siglo XVIII en Lima como símbolo de poder", en El barroco peruano. Vol. 2. Lima, 2003, pp. 135-171; y "Cristobal Lozano, paradigma de la pintura limeña del siglo XVIII", en Actas III Congreso Internacional del Barroco Americano: Territorio, Arte, Espacio y Sociedad, Pablo de Olavide. Sevilla, 2001, pp. 298-316. Puede añadirse WUFFARDEN, Luis Eduardo: "Ilustración versus tradiciones locales", en Pintura en Hispanoamérica: 1550-1820. Madrid, 2014, pp. 365-400; y KUSONOKI RODRÍGUEZ, Ricardo: "De Ruíz Cano a Unanue: Arte y reivindicación criolla en Lima (1755-1806)", Dieciocho. Hispanic Enlightenment, 1, 2006, pp. 107-120. Véase igualmente para el retrato barroco MARTÍNEZ DEL VALLE, Gonzalo: La imagen del poder: el retrato sevillano del siglo XVII. Sevilla, 2010.

${ }^{28}$ Imagen reproducida en WUFFARDEN, L. E.: "Ilustración...", op. cit., p. 368.

${ }^{29}$ A.G.N., Protocolos de..., op. cit., f. 482r. 
que infunde su imponente figura, tomada desde un punto de vista bajo, y el negro de la vestimenta, alusiva a la dinastía de los Habsburgo. La peluca empolvada de origen francés recuerda su importante papel como hombre de leyes. La moda se encuentra también presente en el gusto por el detalle ornamental y en el delicado trabajo de los encajes que llegará a su punto culminante en los retratos femeninos datados en el último tercio del siglo XVIII.

En el segundo plano se localiza una mesa, cubierta quizás de terciopelo verde, cuyos duros pliegues se desbordan, dando una nota de movimiento que encuentra su correlato en el libro abierto. El tercer y cuarto plano repiten estos contrastes: a la estabilidad y orden del plumero, alusivo a su condición de hombre de letras, se pasa al ritmo curvo del cortinaje más cercano al movimiento de la pintura barroca que junto con el libro abierto en el momento de pasar una página parece captar la sensación de lo efímero, cambiante y el temperamento interior de Pedro José Bravo de Lagunas, movido por una fuerte tensión propia de los hombres con inquietudes intelectuales, pero que no era expresada abiertamente en una sociedad, como la limeña del siglo XVIII, tan movida por las apariencias. Asimismo, la cortina otorga mayor nota de color a un cuadro de paleta limitada, en el que destacan tonos oscuros, colores tierra y un tratamiento uniforme de las masas lumínicas. El resto del espacio se resuelve aludiendo a una idea de moderada ostentación. Su origen y cargos quedan expresados en el sector inferior, afirmando el orgullo de ser natural de la ciudad de Lima, hecho clave en un siglo de reivindicación criolla. Por ese mismo motivo se encuentra el escudo de armas de su familia sobre el cortinaje, presentándose como un integrante distinguido de la élite limeña.

La colección de pinturas ha sido documentada a través de su testamento, fechado en 1765, en el apartado titulado "Memoria de las pinturas que dejo en casa para que mi hermano las vincule" 30 con un total de 105 obras. Se trata de una enumeración de piezas en las que siempre consta el título, la posible autoría, que debido al carácter de estos documentos hay que tratar con cautela, y el soporte -lienzo-, incluida una sola lámina. No existe un orden interno específico en las temáticas, que son muy diversas: religiosa, retratos, bodegones, floreros,

${ }^{30}$ Ibidem, ff. 482r-483v. Desafortunadamente el testamento no indica la ubicación del domicilio ni la distribución por salas de las pinturas. Debe pensarse que las distintas habitaciones se fueron especializando, asociándose algunos géneros con la función que ciertos espacios debían cubrir. Así, por ejemplo la sala, que solía ser un lugar de recibo y afirmación de la propia identidad, albergaba los retratos y piezas más exquisitas de asunto sacro o profano. El estudio recogía imágenes que debían conducir a la meditación y el cuarto de dormir incluía advocaciones marianas y santos protectores de la familia, atestiguando una espiritualidad tendiente a la laicización. Véase BARRIGA CALLE, I.: "Modernos e...", op. cit., pp. 438-446. 
mitológica, cuadros de género y paisaje, aunque el asunto profano aparezca con más proliferación al final.

En otros casos especifica las medidas en varas, el formato, escuela, país de procedencia y, en contados momentos, el anterior dueño de la pintura, destacando nombres propios como el de Manuel de Oms y de Santa Pau, marqués de Castelldosríus (1707-1710), vigésimo cuarto virrey del Perú, que tomó posesión del cargo en 1707 y fue embajador desde 1696 en Francia. Fue nombrado virrey tras la Guerra de Sucesión y debió trasladarse al Perú, como era frecuente, con piezas de su colección. Aunque se desconoce el motivo de cómo algunas llegaron a manos de Pedro José Bravo de Lagunas, nos da una idea de la amplia red de contactos y del activo trasiego de piezas, desde España a Lima, así como de la presencia de individuos en Lima que habían residido en Francia y que pudieron ser introductores de nuevas corrientes estéticas que motivara la dedicación de varios maestros limeños del siglo XVIII al género del retrato ${ }^{31}$. Véase como ejemplos de lo que venimos diciendo: "dos excelentes retratos de Luis XIV y del Delfín de manos de Charles Le Brun que trajo de Francia el Virrey Castel dos Ríos, ocho fruteros apaisados flamencos con marcos negros (heredados de su padre), un liencecito apaisado inglés de Adonis y Venus corriente, etc." ${ }^{32}$. Ocasionalmente hace referencia al precio de la obra dando una cantidad exacta. Como ejemplo puede señalarse la pintura con el tema de la Asunción de María, copia de una imagen de Murillo que encarga para el convento de la Buena Muerte, al que se vinculó en vida Bravo de Lagunas, ofreciendo los materiales, concretamente bastidor y tela de mantel fino, con un coste total de doscientos pesos ${ }^{33}$. Acaso debió ser similar,

${ }^{31}$ Para conocer más sobre su vida y actividad en Lima durante su gobierno, así como el papel desempeñado como coleccionista puede verse SALA I VILA, Núria: "La escenificación del poder: el marqués de Castelldosrius, primer virrey borbón del Perú (17071710)", Anuario de Estudios Americanos, 61, 1, 2004, pp. 32-68. Especialmente en las pp. 62-65 la autora nos habla de su colección artística, en la que destacan iconografías ligadas al poder que seguían la moda francesa impuesta por Rigaud como los retratos ya citados de Luis XIV y el Delfín -que salieron al mercado tras su muerte y adquiridos por Pedro José Bravo de Lagunas- junto a dos de Felipe V, unos ecuestre y otro de medio cuerpo, y uno de la reina. Poseyó además varias telas de escenas urbanas -Lima y su plaza, El Callao...-, y cerca de cuarenta países. En su colección predominaron obras de iconografía religiosa, siendo notable la presencia de imágenes de advocaciones criollas como Santa Rosa o la Virgen de Guadalupe, demostrando el interés del virrey por acercarse a las devociones peruanas.

${ }^{32}$ A.G.N., Protocolos de..., op. cit., ff. 482v-483r.

33 Ibidem, f. 482r. Dicha pieza es la única de la que conocemos su valor monetario, elevado para la época, en comparación, por ejemplo, con Quito, en la que la media oscilaba en un rango de 2 a 20 pesos. En Lima, por ahora, las tasaciones han arrojado cifras similares o ligeramente superiores, mayores si se tratan de asuntos sagrados o retratos. Así, por ejemplo, Pedro Bravo de Ribero, oidor de la Real Audiencia, contaba entre sus posesiones, 
aunque no creo que se trate del mismo lienzo, al cuadro de la Coronación de la Virgen, actualmente expuesto en el Palacio Arzobispal de Lima y procedente del templo de San Marcelo tras redistribuirse los bienes de los jesuitas ${ }^{34}$.

La autoría y procedencia de los cuadros es diversa, manifestando un gusto cosmopolita. Podemos encontrar reputados artistas limeños del XVIII como Cristóbal Lozano y Cristóbal Daza en veintitrés y nueve ocasiones respectivamente, junto a representantes extranjeros del barroco europeo: Charles Le Brun (1619-1690) dos veces, Nicolás de Largillière (1656-1746) y Murillo (1617-1682) una vez cada uno, Francisco de Herrera, siete veces -sin especificar si se trata del padre o el hijo-, e, incluso, de particulares como Pablo de la Concha, cuya importante presencia, hasta trece veces, sorprende aunque aún no haya explicaciones claras de quién pudo ser ${ }^{35}$. Tampoco faltan ejemplos de las escuelas más representativas del Viejo Mundo: Venecia, Roma e Inglaterra una vez cada una, España, en nueve ocasiones, confirmando la aceptación de los sistemas ornamentales peninsulares, Flandes, con veintitrés, y, por último, Francia, con ocho, demostrando la presencia en Lima de las formas ilustradas venidas de París, boyante centro artístico durante el siglo XVIII. Esto explica que la escuela alemana y los manieristas venecianos de los siglos XV y XVI, vayan cediendo terreno a temas y autores del XVII, coincidiendo con la independencia de ciertos géneros como el paisaje y el bodegón, mientras que otros, como el retrato, se consolidan debido al Absolutismo.

Además hay muchas pinturas anónimas que podrían relacionarse, por la descripción que se ofrece, con la escuela sevillana o napolitana: "retratos de mudos: con sombreros y gallinas en la mano y retrato de un loco que cuanto tocaba y

según inventario fechado en 1786, un lienzo de Judith en 30 pesos, seis países de escuela española y marcos dorados a 5 pesos cada uno y un San José a 20 pesos. En 1766 Agustín de Frade conservaba una serie completa de pequeño formato con las doce musas a 3 pesos cada ejemplar, una fábula a 6 pesos, tres floreros apaisados a 3 pesos cada uno y dos retratos con marcos negros y dorados a 15 pesos cada unidad, entre otros. Véase A.G.N., Protocolos de Francisco Luque, n 649, 25-8-1786, ff. 463r-464v; y A.G.N., Protocolos de Felipe José Jávara, $\mathrm{n}^{\circ}$ 554, 26-11-1766, f. 166r-v. Consultando las fuentes documentales, observamos que el coleccionismo fue ejercido por varios integrantes de la elite limeña aunque desprovisto, en la mayoría de los casos, de profundidad y careciendo de una aproximación renovadora. Bravo de Lagunas suma a las descripciones agudos comentarios que transforman el documento en un testimonio excepcional para comprender su amor por la pintura.

${ }^{34}$ Véase una buena reproducción en WUFFARDEN, L. E.: "Ilustración...", op. cit., p. 369 .

${ }^{35}$ A.G.N., Protocolos de..., op. cit., ff. 482r-483v. Pudiera ser que Pablo de la Concha no sea un artista sino un caballero de la orden de Calatrava que cultivase la pintura, natural de Lima y autor de del libro Praefecto Militares Arnnonae. Consúltese DE LA MADRID, Antonio: "Montañeses en Portugal", Altamira: Revista del Centro de Estudios Montañeses, 1, 1951, p. 24. 
tenía era real y se llamaba Mago"36. En otros casos se copian los cuadros de género característicos de Bartolomé Esteban Murillo y sus seguidores, demostrando que Bravo de Lagunas tenía interés por la estética naturalista comenzada en la ciudad del Guadalquivir por Juan de Roelas (1570-1625) y continuada por Herrera el Joven (1622-1685), Pedro de Camprobín (1605-1674), José Ribera (15911652) y el ya citado Bartolomé Esteban Murillo: "retrato de un pobre que tiene el sombrero en la mano, de mano de Lozano", o "la copia de dos muchachos golosos comiendo frutas de Lozano" $" 37$.

Es importante detenerse brevemente en estos niños comiendo frutas porque, tal vez, se refiera a una copia o versión de una de las piezas más representativas de la producción de Murillo: los Niños comiendo uvas y melón, datada sobre 1650 y conservada en la Alte Pinakothek de Múnich. La pieza, de su etapa juvenil, muestra a dos niños caracterizados como pícaros, con ropas raídas y gestos de glotonería, sentados en unas ruinas mientras devoran unas uvas y un trozo de melón, captados con una sobresaliente sensación de realidad. El tema tiene sus orígenes en San Diego de Alcalá dándole de comer a los pobres, pintura en la que aparece la atención a la infancia desvalida, propio de Murillo y del que derivaría una escuela de seguidores, pudiéndose establecer una relación directa de este tipo de imágenes con la justicia demandada por el franciscano Martínez de Mata en el "Memorial de la despoblación y pobreza de España y su remedio"38. La pincelada, de mayor

${ }^{36}$ A.G.N., Protocolos de..., op. cit., f. 482r.

${ }^{37}$ Ibidem. Para conocer más sobre la figura de Murillo: ANGULO ÍÑIGUEZ, Diego: Murillo. Vols. I, II y III. Madrid, 1981; y VALDIVIESO GONZÁLEZ, Enrique: Murillo: catálogo razonado de pinturas. Madrid, 2010.

38 Sobre la trascendencia de Murillo véase HELLWIG, Karin: "La recepción de Murillo en Europa”, en El Joven Murillo. Bilbao, 2009, pp. 97-115; y, especialmente, GARCÍA FELGUERA, María de los Santos: La fortuna de Murillo (1682-1900). Sevilla, 1989. En la Sevilla de la segunda mitad del siglo XVII la figura de Murillo fue constantemente alabada y su particular estilo adoptado por otros artífices. Entre los elogios más destacados se encuentran los pronunciados por Fernando de la Torre Farfán como, por ejemplo, el Apeles sevillano. Igualmente este mismo autor indica cómo en 1671 los cuadros de Murillo habían trascendido el ámbito español, sin pasar por la corte. Para el conocimiento del pintor fuera de España durante épocas posteriores fueron decisivos el puerto de Sevilla, las relaciones de Murillo con clientes flamencos, ingleses y rusos, vinculados a la diplomacia, y la biografía contenida en la Academia Picturae Eruditae de Sandrart (1683). Para conocer más sobre Murillo a finales del siglo XVII véase las pp. 31-39 del citado trabajo. En Inglaterra durante la primera mitad del siglo XVIII Murillo fue adquiriendo una importancia creciente debido a la temprana traducción del libro de Palomino, hecho que explica la existencia de importantes colecciones pictóricas como la de Sir Robert Walpole (1720), con cinco ejemplares del maestro sevillano, y la realización de copias por Gainsborough y Reynolds (véase pp. 45-54). Finalmente, hasta la invasión napoleónica no se generó un verdadero interés en Francia por Murillo (pp. 97-127), si bien su presencia en colecciones particulares españolas durante buena parte del siglo XVIII fue bastante reseñable en el 
soltura, y los efectos de vaporosidad muestran la influencia que adquirió de Herrera el Joven y la pintura veneciana. El mundo holandés se encuentra presente en la atención y recreación a la vida quieta como en el caso de la cesta de mimbre rota. Fue adquirido por el príncipe elector Maximiliano Emanuel de Baviera durante su estancia en Bruselas, entre 1692 y 1701, como gobernador de los Países Bajos, junto a los Niños jugando a los dados ${ }^{39}$. Murillo aplica su retina a las escenas cotidianas, hecho que une a una técnica rica en materia pictórica resaltando los contornos de las figuras. Hay una importante filiación con el naturalismo de Caravaggio (1593-1610) en los pies descalzos y la iluminación claroscurista, creando un prototipo pictórico universal y de gran fortuna.

La existencia de una copia de esta pintura permite afirmar que Murillo fue un artista conocido y valorado durante el siglo XVII y XVIII en Lima, adquiriendo un claro sentido internacional y una fama en correspondencia de la que gozó en el resto de Europa. Como ha estudiado Karin Hellwig era el pintor por antonomasia y sus cuadros alcanzaban grandes precios en las subastas, siendo tan solicitados que Carlos III dictó una disposición que prohibía en 1779 la exportación de obras de arte españolas, en virtud de los rumores que corrían sobre extranjeros que pretendían adquirir obras de Murillo y otros pintores. Por otra parte, tenemos pruebas del impacto de este asunto muchos años antes, así como sus posibles fuentes literarias, en el testimonio transmitido por fray Juan Meléndez en 1671, narrando la decoración de la portería del convento de Santo Domingo de Lima, con motivo de las fiestas de la beatificación de Santa Rosa, que consistía en temas de pintura y escultura. En uno de ellos describe a dos jóvenes descuartizando un melón y desgajando dos grandes racimos de uvas "a la manera que suelen andar pintados, no sé si aludiendo al cuento de aquellos dos picarillos, que anda entre ciertas novelas" ${ }^{\prime 4}$.

Atendiendo a la temática de las pinturas se pone de manifiesto el decreciente interés por lo sagrado. Concretamente, de asunto religioso, incluyendo también algunos países de historia sacra, nos encontramos con un $24,47 \%$ del total, mientras que el $75,53 \%$ restante pertenece a la temática profana-porcentaje elaborado

ámbito de la corte -Isabel de Farnesio, Carlos III y Carlos IV- y en Sevilla con Francisco de Bruna, el marqués de Loreto y Antonio Maestre, entre otros (pp. 133-139).

${ }^{39}$ Véase para un análisis estilístico en profundidad de la pieza, incluida su procedencia, la ficha contenida en NAVARRETE PRIETO, Benito y PÉREZ SÁNCHEZ, Alfonso Emilio: El Joven Murillo. Bilbao, 2009, pp. 252-257. Posiblemente en Amberes antes de 1659, documentada en Amberes en el inventario del jefe de correos Jaan Bapte Anthoine, $\mathrm{n}^{\circ}$ 95, 1687, figurando dos copias más de esta obra. Adquirido por Maximiliano II Emmanuel, gobernador de los Países Bajos, Amberes, hacia 1691. Inventariado en la Residenz, Múnich, ya en 1748; documentado en la Hofgartengalerie, Múnich, ya en 1781; Alte Pinakothek, Múnich, 1836.

${ }^{40}$ RAMOS SOSA, Rafael: Arte festivo en Lima virreinal: siglos XVI-XVII. Sevilla, 1992, pp. 229-230. 
sobre 94 ejemplares porque de once no tenemos noticias-, especialmente escenas de género cercanas al naturalismo de Caravaggio y, como venimos señalando, a la estética de Murillo. Véase a modo de ejemplo: "un lienzo de Morillo de un soldado con la cara de medio perfil y una gitana diciéndole la buenaventura, y un gitano hurtándole una gallina y un muchacho admirado, un retrato de mano de Largillière que costó mucho dinero y un lienzo de una canasta de frutas con un lorito, y un escarabajo con una liebre, conejo y cochino colgando, pieza de especial gusto, y que fue de mi padre y la he apreciado con particularidad" ${ }^{41}$. Sorprende la relevancia que adquieren los asuntos considerados menores por los académicos de la época, destacando la afición por el bodegón, tema amable y decorativo que se encuentra en un $28,72 \%$, y los cuadros de risa y género en un $8,51 \%$. El retrato, género noble según los tratadistas, tiene una notable presencia con un 21,28\%, y los paisajes, varios mitológicos, un 17,02\%.

La pintura religiosa responde a la tónica general de las colecciones pictóricas tradicionales: cabezas de mártires, santos en meditación -San Francisco, San Mateo la Magdalena...-, la Virgen con el Niño, la Purísima Concepción de María, la Encarnación, escenas dulces y amables de la infancia de Jesucristo -el Nacimiento- y de su adultez -el Bautismo-, parábolas del Nuevo Testamento, y milagros como los de Santo Toribio, una Escalera de Jacob y la Muerte de San José ${ }^{42}$. Sintomática resulta la ausencia de ejemplos del ciclo de la Pasión de Cristo, frecuente en Lima durante toda la Edad Moderna. Ciertamente en el siglo XVIII se recuperó la estética clásica debido a los nuevos aires ilustrados. Esto no quiere decir que durante el Siglo de las Luces el ambiente religioso de las décadas precedentes desaparezca. Incluso parece que tanto en España como en América persiste. Así aparece reflejado en el testamento cuando Bravo de Lagunas hace referencia a un lienzo con el tema del Nacimiento, afectado por el seísmo de 1746, de una técnica no demasiado depurada "que quedará por servir a la devoción y por ser sabido de un amigo"43.

Esta afirmación tan sugerente pone de manifiesto un aspecto de la funcionalidad de la obra de arte religiosa desde el siglo XVI en territorio americano, cuyo objetivo era facilitar la evangelización. Siguiendo los datos ofrecidos por el testamento, considero que Pedro José Bravo de Lagunas tenía un amplio conocimiento artístico e intentaba comprar pinturas de alto valor estético porque posiblemente debieron ser colocadas en lugares estratégicos del espacio doméstico y mostradas al público en el acto de enseñar la casa. La prueba de todo esto se encuentra en su testamento al referirse a obras que sufrieron desperfectos debido al terremoto ya citado y "cuyos retoques las han hecho tan intolerables que

\footnotetext{
${ }^{41}$ A.G.N., Protocolos de..., op. cit., f. 483v.

${ }^{42}$ Ibidem, ff. 482v-483r.

${ }^{43}$ Ibid., f. 483r.
} 
son necesarios quitar de la vista" ${ }^{44}$, testimonio que deja adivinar un proceso de colección durante décadas.

Además, emplea juicios de valor deteniéndose en factores compositivos y cromáticos, atestiguando su manera renovada de ver y sentir el arte: "un lienzo grande de la Parábola del samaritano muy particular, un lienzo de una mujer tragona emborrachándose corriente, un lienzo de San José expirando con una técnica de buen azul, un país con cacería y frutas bastantes y colores finos, etc..."45. Por todo lo dicho, Bravo de Lagunas sería un coleccionista puro que adquiere arte porque tiene las necesidades básicas cubiertas, siendo este acto una expresión de la mejora del estilo de vida. También busca diferenciarse, gratificándose de su posición, con la posesión de objetos exclusivos que puede disfrutar contemplando diariamente. Por último, atesora siguiendo un criterio estético, siendo conocedor de la calidad de las pinturas, aunque en ciertos casos mantiene algunos ejemplos en su colección por vinculaciones puramente sentimentales. De manera resumida, la galería recopilada por Bravo de Lagunas fue la siguiente:

Colección pictórica de Pedro José Bravo de Lagunas (1703-1765)

\begin{tabular}{|l|c|l|}
\hline \multicolumn{1}{|c|}{ Asunto } & Cantidad & \multicolumn{1}{c|}{ Otras observaciones } \\
\hline $\begin{array}{l}\text { La Asunción } \\
\text { de María }\end{array}$ & 1 & $\begin{array}{l}\text { De mano de Lozano, copia de otra obra similar de Muri- } \\
\text { llo y pintada por 200 pesos. }\end{array}$ \\
\hline Retratos & 4 & $\begin{array}{l}\text { D. Mauro de Mendoza, el marqués de Monroy, otro pe- } \\
\text { queño del marqués de Villagarcía (los tres de Lozano) y } \\
\text { el cardenal de Mendoza (pintado en Madrid, anónimo). }\end{array}$ \\
\hline Retrato & 1 & $\begin{array}{l}\text { Pequeño, de mano de Lozano, representando al conde de } \\
\text { Villa Señor. }\end{array}$ \\
\hline Mitología & 4 & $\begin{array}{l}\text { Dos lienzos apaisados, de mano de Lozano, copiando } \\
\text { piezas venecianas llevadas a Lima por el príncipe de } \\
\text { Santo Buono y otros dos anónimos de Melpómene y } \\
\text { otra musa de pie con un perro, no identificada. Se indica } \\
\text { que existían más de estos lienzos pero sufrieron desper- } \\
\text { fectos en el terremoto de 1746 y no se vinculan debido a } \\
\text { las desafortunadas restauraciones. }\end{array}$ \\
\hline $\begin{array}{l}\text { Retrato de un } \\
\text { pobre }\end{array}$ & 1 & \begin{tabular}{l} 
Pintado por Lozano. \\
\hline
\end{tabular}
\end{tabular}
44 Ibid.
45 Ibid.

LABORATORIO DE ARTE 29 (2017), pp. 503-524, ISSN 1130-5762 e-ISSN 2253-8305 - DOI http://dx.doi.org/10.12795/LA.2017.i29.28 


\begin{tabular}{|c|c|c|}
\hline $\begin{array}{l}\text { Retratos de } \\
\text { mudos }\end{array}$ & 2 & Pintados por Lozano. \\
\hline $\begin{array}{l}\text { Retrato de un } \\
\text { pintor }\end{array}$ & 1 & Llamado Lorenzo Ferrer y pintado por Lozano. \\
\hline David & 2 & Una copia de mano de Lozano y un original de Daza. \\
\hline $\begin{array}{l}\text { Retrato de un } \\
\text { loco }\end{array}$ & 1 & Llamado “Mago” y pintado por Lozano. \\
\hline $\begin{array}{l}\text { Escena de gé- } \\
\text { nero }\end{array}$ & 1 & $\begin{array}{l}\text { Dos muchachos comiendo frutas, copia de mano de Lo- } \\
\text { zano. }\end{array}$ \\
\hline $\begin{array}{l}\text { Retratos de bo- } \\
\text { rrachos }\end{array}$ & 2 & $\begin{array}{l}\text { El primero nombrado "Cacimiro" y el segundo "Orella- } \\
\text { nita el Fuerte", ambos de Lozano. }\end{array}$ \\
\hline $\begin{array}{l}\text { Retrato de una } \\
\text { mujer }\end{array}$ & 1 & Pintado por Lozano. \\
\hline $\begin{array}{l}\text { Retrato de } \\
\text { Merlín }\end{array}$ & 1 & Pintado por Lozano. \\
\hline $\begin{array}{l}\text { Escenas de gé- } \\
\text { nero }\end{array}$ & 3 & $\begin{array}{l}\text { Tres lienzos de lozano (uno de un hombre con naipes en } \\
\text { la mano, otro con un papel, y una mujer entrando en un } \\
\text { gallinero). }\end{array}$ \\
\hline $\begin{array}{l}\text { Cabeza de San } \\
\text { Ignacio }\end{array}$ & 1 & Copia, de mano de Lozano. \\
\hline San Francisco & 1 & $\begin{array}{l}\text { Copia de una pieza del Greco, lienzo pintado por Lo- } \\
\text { zano. }\end{array}$ \\
\hline La Purísima & 1 & De mano de Daza y dos varas de alto. \\
\hline La Magdalena & 1 & De mano de Daza. \\
\hline $\begin{array}{l}\text { Países (unos } \\
\text { religiosos y } \\
\text { otros profa- } \\
\text { nos) }\end{array}$ & 4 & $\begin{array}{l}\text { Narciso, Andrómeda y un Nacimiento, pintados por } \\
\text { Daza, y otro Narciso anónimo. }\end{array}$ \\
\hline $\begin{array}{l}\text { La Escalera de } \\
\text { Jacob }\end{array}$ & 1 & Apaisada. \\
\hline $\begin{array}{l}\text { La Cena de } \\
\text { Baltasar }\end{array}$ & 1 & Antiguo. \\
\hline
\end{tabular}




\begin{tabular}{|c|c|c|}
\hline $\begin{array}{l}\text { La Encarna- } \\
\text { ción }\end{array}$ & 1 & Lámina antigua de la casa. \\
\hline $\begin{array}{l}\text { San Francisco } \\
\text { de Paula }\end{array}$ & 1 & Lienzo traído de Francia por el virrey Castelldosríus. \\
\hline $\begin{array}{l}\text { Bautismo de } \\
\text { Cristo }\end{array}$ & 1 & "Muy particular", que fue del conde de Canillas. \\
\hline Santo Toribio & 1 & Lienzo pequeño. \\
\hline $\begin{array}{l}\text { Temas indeter- } \\
\text { minados }\end{array}$ & 4 & Lienzos menores de media vara, procedentes de Francia. \\
\hline $\begin{array}{l}\text { Escenas de gé- } \\
\text { nero }\end{array}$ & 2 & Un gitano y una gitana riéndose. \\
\hline Retratos & 2 & $\begin{array}{l}\text { De Luis XIV y el Delfín, su autor Charles Le Brun y } \\
\text { traídos de Francia por el virrey Castelldosríus. Son exce- } \\
\text { lentes. }\end{array}$ \\
\hline Parábola & 1 & El buen samaritano, "muy particular". \\
\hline Retrato & 1 & Príncipe de Santo Buono, escuela de Tiziano. \\
\hline Bodegones & 12 & $\begin{array}{l}\text { Cuatro de pequeño formato y ocho de escuela flamenca, } \\
\text { apaisados y con marcos negros, todos "muy finos". }\end{array}$ \\
\hline Mitología & 1 & Adonis y Venus, “corriente" y de procedencia inglesa. \\
\hline $\begin{array}{l}\text { Países (unos } \\
\text { religiosos y } \\
\text { otros profa- } \\
\text { nos) }\end{array}$ & 12 & $\begin{array}{l}\text { El Arca de Noé, los montes de Armenia, los altares de la } \\
\text { Virgen (de Daza), una batalla de moros, una cacería "de } \\
\text { colores finos", uno de la batalla de Pavía "muy bueno", } \\
\text { cinco flamencos (dos fábulas, un nacimiento de Moisés y } \\
\text { dos santas), una vista pintada por Daza del "Lechugal". }\end{array}$ \\
\hline Retratos & 2 & Felipe V y "la Reina Saboyana". \\
\hline $\begin{array}{l}\text { Escena de gé- } \\
\text { nero }\end{array}$ & 1 & Mujer borracha "corriente". \\
\hline San José & 1 & Expirando y "con una técnica de buen azul". \\
\hline María y José & 1 & $\begin{array}{l}\text { Lienzo apaisado antiguo en la casa, de pequeño formato } \\
\text { y origen romano. }\end{array}$ \\
\hline
\end{tabular}




\begin{tabular}{|c|c|c|}
\hline El Nacimiento & 1 & $\begin{array}{l}\text { "Apaisado, regular y con algunos defectos quedará por } \\
\text { devoción y por ser sabido de un amigo". }\end{array}$ \\
\hline Bodegones & 13 & $\begin{array}{l}\text { Apaisados, su autor Pablo de la Concha y "muy celebra- } \\
\text { dos" por ser de escuela flamenca. }\end{array}$ \\
\hline País & 1 & Zorra cazando un gallo que "costó mucho dinero". \\
\hline $\begin{array}{l}\text { Escena de gé- } \\
\text { nero }\end{array}$ & 1 & $\begin{array}{l}\text { Representa un soldado al que le dicen la buenaventura } \\
\text { mientras le hurtan una gallina. Pieza de Murillo. }\end{array}$ \\
\hline Retrato & 1 & $\begin{array}{l}\text { Francés, de mano de Largillière, "que costó mucho di- } \\
\text { nero". }\end{array}$ \\
\hline Bodegón & 1 & $\begin{array}{l}\text { Por ser una pintura heredada de su padre, Bravo de La- } \\
\text { gunas la estima especialmente. }\end{array}$ \\
\hline Bodegón & 1 & Una langosta, con pan y frutas. \\
\hline $\begin{array}{l}\text { Temas indeter- } \\
\text { minados }\end{array}$ & 7 & $\begin{array}{l}\text { De gran formato, su autor Francisco de Herrera (sin } \\
\text { aclarar si se trata del padre o del hijo) }\end{array}$ \\
\hline Total & 105 & \\
\hline
\end{tabular}

En cuanto a la psicología del coleccionista, Henri Codet estableció una clasificación de cuatro móviles: el deseo de propiedad, de perfección intelectual, de ser mejor que los demás y de etiquetar, ordenar y clasificar la realidad, presente en el testamento en el momento en que Bravo de Lagunas apuesta por seguir un orden temático, refiriendo la autoría y procedencia de algunos lienzos ${ }^{46}$. También podría señalarse el deseo de perfección intelectual, porque nuestro coleccionista fue dueño de una biblioteca que contaba con libros de todas las materias y que nos recuerda la unión existente entre pintura y poesía, asunto de importante fecundidad en la teoría artística, renovado desde el Renacimiento bajo el topos latino Ut Pictura Poesis. Obviamente, ningún documento puede demostrarnos que todos los ejemplares fuesen leídos, pero el simple hecho de poseerlos y su desempeño como catedrático en la Universidad de San Marcos nos lo presenta como un personaje con inquietudes intelectuales. Finalmente, el afán de demostrar su estatus dentro de la estratificada sociedad barroca podría ser otro de los motores que motivó la formación de una importante colección pictórica.

${ }^{46}$ PEARCE, Susan Mary: Museums, objects and collections: a cultural study. Londres, 1992, pp. 36-88; y CODET, H.: Ensayo..., op. cit. 
En conclusión, Pedro José Bravo de Lagunas fue un coleccionista que valoró temas y cuestiones de la pintura contemporánea europea, hecho que dota a su colección de una indiscutible modernidad. Los datos proporcionados por el inventario, si bien no son todo lo completos que desearíamos, contemplan aspectos como la autoría de algunas piezas, tamaño, estilo y procedencia, constituyendo así una aportación documental representativa para recrear el perfil de un coleccionista sensible y culto en la Lima del XVIII.

Este tipo de fuente notarial puede ayudar a conocer y delimitar el estudio artístico de la pintura limeña. Es de suponer que al ser corte y capital del virreinato llegarían antes o después las distintas corrientes estilísticas de la pintura internacional. Por otro lado, la colección significa la más que posible presencia de otros coleccionistas que formaban parte de un público culto que sabía apreciar el arte de la pintura. Entre ellos quizás existiera una cierta competición, hecho que pudo ocasionar la aparición de diversas especializaciones dentro de las colecciones pictóricas. Hipótesis y posibilidades que seguiremos investigando.

Fecha de recepción: 1 de abril de 2016

Fecha de aceptación: 31 de enero de 2017 


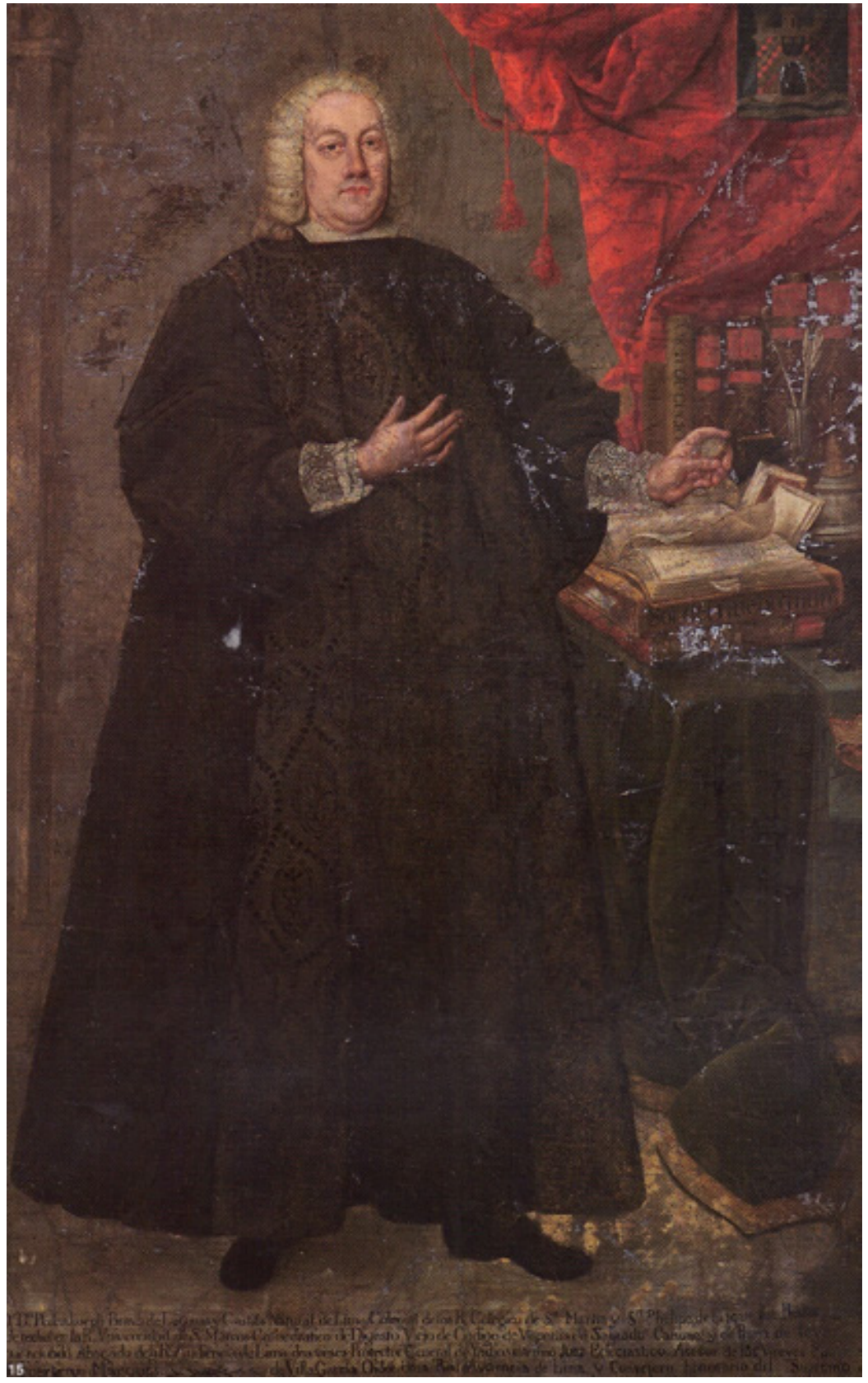

Figura 1. Cristóbal Lozano, Retrato de Pedro José Bravo de Lagunas, 1752, colección Casa Aliaga.

LABORATORIO DE ARTE 29 (2017), pp. 503-524, ISSN 1130-5762

e-ISSN 2253-8305 - DOI http://dx.doi.org/10.12795/LA.2017.i29.28 